\title{
Molecular Similarity Relationships Among Iranian Bread Wheat Cultivars and Breeding Lines Using ISSR Markers
}

\author{
Sahar DASHCHI ${ }^{1}$, Babak ABDOLLAHI MANDOULAKANI ${ }^{1,2 *}$, \\ Reza DARVISHZADE ${ }^{1,2}$, Iraj BERNOUSI ${ }^{1,2}$ \\ ${ }^{1}$ Urmia University, Faculty of Agriculture, Department of Agronomy and Plant Breeding, \\ Urmia,Iran; b.abdollabi@urmia.ac.ir ("corresponding author) \\ ${ }^{2}$ Urmia University, Institute of Biotechnology, Department of Agricultural biotechnology, Urmia, Iran
}

\begin{abstract}
Inter simple sequence repeat (ISSR) markers were used to characterize and assess genetic diversity of Iranian bread wheat (Triticum aestivum L.) using 101 cultivars and breeding lines. Twenty-three ISSR primers amplified a total of 267 loci, of which 224 (83.9\%) were polymorphic among the genotypes. The percentage of polymorphic loci (PPL) for primers ranged from 54\% (UBC808) to $100 \%$ (441, A12 and UBC820). The mean of expected heterozygosity (He) for the primers varied from 0.26 (UBC808, UBC827 and A14) to 0.48 (A12, 441). The PPL, He, Shannon's information index (I), and number of effective alleles ( Ne) for breeding lines were slightly higher than those of cultivars. The Dice similarity coefficient for the germplasm ranged from 0.76 (between two breeding lines) to 0.91 (between two breeding lines). The dendrogram grouped samples in four main clusters; most cultivars were placed into the same cluster close to each other with regard to their geographic origin. The genotypes in different groups might be used as potential parents in bread wheat breeding programs. Also, a high level of genetic similarity detected in this collection may demonstrate the narrow genetic base of Iranian wheat germplasm.
\end{abstract}

Keywords: expected heterozygosity, genetic variability, Shannon's information index, Triticum aestivum L.

\section{Introduction}

Bread wheat (Triticum aestivum L.), the most important cereal crop in the world, evolved from wild grasses, probably somewhere in the Near East (Briggle and Curtis, 1987). In the cradle of agriculture, Iran is considered as the centre of origin of wheat and as a primary centre of its genetic diversity, but Iranian wheat germplasm has experienced an overall reduction in its genetic basis as a result of high selection pressure, recurrent use of the adapted elite germplasm, and the adoption of particular breeding schemes.

Genetic diversity patterns can provide insights into evolutionary and demographic history of a taxon. Moreover, exploitation, evaluation, and strategies for the conservation in situ and ex situ of genetic diversity present in natural populations or local cultivars are imperative to guarantee sustainable development (Smolik et al., 2011). Dreisigacker et al. (2005) reported that the genetic variation of bread wheat landraces and cultivars conserved in seed banks is usually unknown. Thus, in many countries, strategies have been devoted to characterize and evaluate the genetic diversity of their natural populations and landraces, providing considerable opportunities for genetic research, breeding, and construction of core collections (Hou et al., 2005).

Genetic diversity among individuals or populations can be determined using morphological and molecular markers. Phenotypic characters have limitations since they are influenced by environmental factors and the developmental stage of the plant (Archak et al., 2003). Different molecular marker systems have been used to assess genetic diversity in wheat, including random amplified polymorphic DNA (RAPD) (Abdollahi Mandoulakani et al., 2010), amplified fragment length polymorphism (AFLP) (Khalighi et al., 2008), simple sequence repeats (SSRs) (Gupta et al., 2002), sequence-tagged-sites (STS) (Talbert et al., 1994), and retrotransposon-based markers (Carvalho et al., 2010). Inter simple sequence repeat (ISSR) markers is a PCR-based technique, amplify regions between adjacent and inversely oriented microsatellites using di-, tri-, tetra-, and penta-nucleotide SSR primers, with the advantage that knowledge of the DNA sequence of the target region is not required. ISSR amplification depends on the variation, motif, and frequency of SSRs that change among species (Zietkiewicz et al., 1994). ISSR is an ideal method for fingerprinting and a useful alternative to single-locus or hybridization-based methods. It is a powerful technique to determine intra- and inter-specific genetic diversity (Bornet and Branchard, 2001; Myśków et al., 2011; Pradeep Reddy et al., 2002; Smolik et al., 2011; Sofalian et al., 2009). The ISSR markers are increasingly applied in the plant sciences and have detected a sufficient degree of polymorphism in faba bean (Terzopoulos and Bebeli, 2008), safflower (Golkar et al., 2011), rice (Blair et al., 1999) and barley (Hou et al., 2005). ISSR mark- 
ers have a better reproducibility than RAPDs, are easy to detect and can be produced at lower costs than AFLPs. They are simpler to use than the SSR technique and less restrictive than restriction fragment length polymorphism (RFLP), and may offer considerable variation among species (Archak et al., 2003)

In order to extend the genetic base of Iranian wheat collection, new breeding lines have been currently introduced to this germplasm. To the best of our knowledge, little information is available on the molecular diversity of Iranian wheat cultivars and breeding lines using ISSR markers. Therefore, the objective of our study were to characterize 101 Iranian bread wheat cultivars and breeding lines using cultivar-specific ISSR markers and to assess the genetic diversity and relationships among the cultivars and breeding lines for further planning of germplasm conservation and breeding strategies.

\section{Materials and methods}

\section{Plant materials and DNA isolation}

Fifty Iranian wheat cultivars and 51 breeding lines provided by the Seed and Plant Improvement Institute, Karaj, Iran, were used (Tab. 1). Seeds were planted in small pots with a $10 \mathrm{~cm}$ diameter, containing a mixture of garden soil and vermiculite, in the greenhouse with $20^{\circ} \mathrm{C}$ of ambient

Tab. 1.101 bread wheat cultivars and breeding lines used in the current study

\begin{tabular}{ccccc}
\hline Cultivar & Cultivar & $\begin{array}{c}\text { Breeding } \\
\text { line }\end{array}$ & $\begin{array}{c}\text { Breeding } \\
\text { line }\end{array}$ & $\begin{array}{c}\text { Breeding } \\
\text { line }\end{array}$ \\
\hline 'Adl' & 'Karaj3' & 2 & 140 & 1720 \\
\hline 'Alamut' & 'Kaveh' & 5 & 145 & \\
\hline 'Akbari' & 'Kavir' & 8 & 146 & \\
\hline 'Arta' & 'Mahdavi' & 12 & 147 & \\
\hline 'Aria' & 'Marvdasht' & 13 & 149 & \\
\hline 'Atrak' & 'Moghan1' & 15 & 151 & \\
\hline 'Azadi' & 'Moghan3' & 16 & 152 & \\
\hline 'Bam' & 'Morvarid' & 18 & 156 & \\
\hline 'Bahar' & 'M17' & 19 & 158 & \\
\hline 'Behrang' & 'Navid' & 20 & 159 & \\
\hline 'Bayat' & 'Niknezhad' & 22 & 164 & \\
\hline 'Chenab' & 'Pishgam' & 25 & 167 & \\
\hline 'Darab2' & 'Rasul' & 28 & 168 & \\
\hline 'Darya' & 'Roshan' & 30 & 169 & \\
\hline 'Dena' & 'Sardari' & 32 & 170 & \\
\hline 'Dez' & 'Sepahan' & 38 & 175 & \\
\hline 'Falat' & 'Shahpasnd' & 110 & 177 & \\
\hline 'Gaskozhen' & 'Shahriar' & 114 & 178 & \\
\hline 'Gaspard' & 'Shiraz' & 115 & 179 & \\
\hline 'Ghods' & 'Sholeh' & 121 & 183 & \\
\hline 'Golestan' & 'Sorkhtokhm' & 122 & 608 & \\
\hline 'Hamun' & 'Sistan' & 125 & 1546 & \\
\hline 'Hirmand' & 'Vee/nak' & 132 & 1549 & \\
\hline 'Inia' & 'Zagros' & 133 & 1661 & \\
\hline Karaj2' & 'Zarin' & 137 & 1717 & \\
\hline & & & & \\
\hline
\end{tabular}

temperature. Genomic DNA was extracted from young leaves of 20 day seedlings of five plants from each genotype using the method described by Doyle and Doyle (1990) with minor modifications. The concentration of genomic DNA samples was determined by a spectrophotometer and by $0.8 \%$ agarose gel electrophoresis.

\section{ISSR analysis}

Fifty-seven ISSR primers were tested on three cultivars and three breeding lines to choose the primers yielding a clear, scorable, and discernible banding pattern (Tab. 2). Gradient PCR was used to optimize the annealing temperature of each primer. PCRs were carried out in a BioRad thermocycler (Bio-Rad Laboratories Inc., Hercules, CA, USA). Each $20 \mu \mathrm{l}$ of the reaction contained $30 \mathrm{ng}$ of genomic DNA, $1 \times$ PCR buffer $(10 \mathrm{mM}$ Tris-HCL, $50 \mathrm{mM}$ KCL, $\mathrm{PH}=8.3), 1.5 \mathrm{mM} \mathrm{MgCl}, 0.2 \mu \mathrm{M}$ dNTP, $0.5 \mathrm{U}$ Taq DNA polymerase and 10 picomol primer. The thermal profile for ISSR-PCR was as follows: $94^{\circ} \mathrm{C}$ initial denaturation for $4 \mathrm{~min}$, then 35 cycles of $94^{\circ} \mathrm{C}$ for $40 \mathrm{~s}, 53$ to $61^{\circ} \mathrm{C}$ (Tab. 2) for $40 \mathrm{~s}$, and $72^{\circ} \mathrm{C}$ for $2 \mathrm{~min}$, then $72^{\circ} \mathrm{C}$ for $5 \mathrm{~min}$. ISSR bands were separated by electrophoresis in $1.8 \%$ agarose gels (Trade Mark) and visualized with ethidium bromide $\left(1.0 \mathrm{ugml}^{-1}\right)$. The electrophoretic patterns of the PCR products were photographed under UV light using a Gel-Doc image analysis system (Gel Logic $212 \mathrm{PRO})$.

\section{Data analysis}

For subsequent statistical analysis, ISSR markers were binary-coded using 1 for presence and 0 for absence of band in each genotype. The genetic similarity matrix derived from ISSR data were calculated between 101 genotypes using the Dice similarity coefficient and subsequently used to construct the dendrogram using the complete linkage algorithm. To verify the adjustment between similarity matrix and respective dendrogram-derived matrix (cophenetic matrix), the cophenetic correlation coefficient was estimated. A similarity matrix were also used to establish the dcenter matrice and subsequently used to accomplish principal coordinate analysis (PCoA) to resolve the patterns of genetic relationships among 101 studied genotypes. All of these computations were implemented in NTSYSpc 2.1 (Rohlf, 2000). Number of loci, percentage of polymorphic loci (PPL), number of loci with a frequency higher or equal to $5 \%$, number of private or specific loci, number of less common loci with frequency lower or equal to $25 \%$ and $50 \%$, mean of expected heterozygosity $(\mathrm{He})$, Shannon's information index (I) and number of effective alleles (Ne) (Lynch and Milligan, 1994) were also calculated for each primers as well as for cultivars, breeding lines and cultivars + breeding lines using GenAlEx 6.41 software (Peakall and Smouse, 2006). To partition of total genetic variation within and among cultivars and breeding lines, analysis of molecular variance (AMOVA) was carried out with this software as well. 
Tab. 2. The primer sequences and annealing temperatures used in the study

\begin{tabular}{|c|c|c|c|c|c|}
\hline Primer & Sequence $\left(5^{\prime}-3\right)^{\prime}$ & $\begin{array}{l}\text { Annealing } \\
\text { temperature }\end{array}$ & Primer & Sequence $\left(5^{\prime}-3\right)^{\prime}$ & $\begin{array}{l}\text { Annealing } \\
\text { temperature }\end{array}$ \\
\hline UBC 818 & $(\mathrm{CA})_{8} \mathrm{G}$ & 54 & UBC 864 & (ATG)6 & 53 \\
\hline 441 & $(\mathrm{TG})_{9} \mathrm{C}$ & 61 & UBC 855 & $(\mathrm{AC})_{8} \mathrm{YT}$ & 56 \\
\hline UBC 807 & $(\mathrm{AG})_{8} \mathrm{~T}$ & 54 & UBC816 & $(\mathrm{CA})_{8}^{0} \mathrm{~T}$ & 53 \\
\hline UBC 808 & $(\mathrm{CA})_{7} \mathrm{G}$ & 54 & UBC 827 & $(\mathrm{AC})_{8} \mathrm{G}$ & 58 \\
\hline $\mathrm{A} 13$ & $(\mathrm{GT}){ }_{6} \mathrm{CC}$ & 55 & UBC 812 & $(\mathrm{GA})_{8} \mathrm{~A}$ & 53 \\
\hline UBC 840 & $(\mathrm{GA})_{8} \mathrm{Y}^{*} \mathrm{~T}$ & 54 & UBC 811 & $(\mathrm{GA})_{8}^{8} \mathrm{C}$ & 54 \\
\hline UBC 825 & $(\mathrm{AC})_{8} \mathrm{~T}$ & 55 & UBC 834 & $(\mathrm{AG})_{8} \mathrm{YT}$ & 55 \\
\hline UBC 848 & $(\mathrm{CA})_{8} \mathrm{R}^{*} \mathrm{G}$ & 54 & A12 & $(\mathrm{GA})_{6} \mathrm{CC}$ & 53 \\
\hline A15 & $(\mathrm{AG})_{6} / \mathrm{RG}$ & 55 & UBC 836 & $(\mathrm{AG})_{7} \mathrm{YA}$ & 55 \\
\hline A14 & $(\mathrm{CA})_{6} / \mathrm{AC}$ & 54 & UBC 844 & $(\mathrm{CT})_{8} \mathrm{RC}$ & 56 \\
\hline UBC 857 & $(\mathrm{AC})_{8} \mathrm{YG}$ & 57 & UBC 820 & $(\mathrm{GT})_{8} \mathrm{C}$ & 55 \\
\hline UBC 880 & $(\mathrm{G}(\mathrm{GA}) 2) 3$ & 53 & & & \\
\hline
\end{tabular}

*Y: C or T, R: A or T

\section{Results}

In the present study, out of 57 ISSR primers screened, 23 anchored dinucleotide primers amplified 267 clear and discernible loci which 224 were polymorphic (83.9\%) (Tab. 2 and 3). No cultivar- or breeding line-specific marker was produced. The frequency of all amplified loci was more than $5 \%$. No less common loci with frequency lower than $50 \%$ were amplified. The number of total loci per primer ranged from 7 (UBC844) to 16 (UBC811), with an average of 11.6. The number of polymorphic loci per primer ranged from 5 to 14 with a mean value of 9.78 . The
PPL, He, I, and Ne were calculated in order to characterize the capacity of each primer to detect polymorphism and to evaluate the discriminating ability of each primer in this collection. PPL detected by primers UBC840, UBC820 and A12 were $100 \%$. UBC 808 generated 54\% polymorphism in the studied germplasm. The polymorphism detected by primers A13 and UBC840 are presented in Fig. 1 and 2 , respectively. The size of the amplified fragments ranged from 75 to $2000 \mathrm{bp}$. He for primers varied from 0.26 (UBC808, A14, UBC827) to $0.48(\mathrm{~A} 12,441)$ averaging 0.36 (Tab. 3 ).

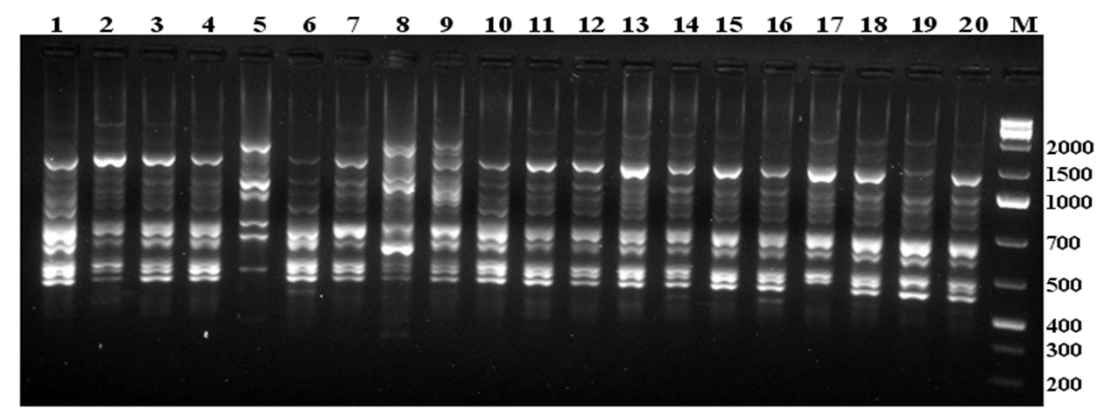

Fig. 1 . The ISSR profiles obtained by primer A13, lanes 1 to 20: Pishgam, Darya, Moghan3, Dez, 121, 608, 1549, 149, 1720, Adl, Golestan, Shiraz, Rasol, 122, Shahpasand, Sorkh tokhm, Alamot, Akbari, 1661, 20, M: 1 kb DNA ladder (Fermentas, SM1303)

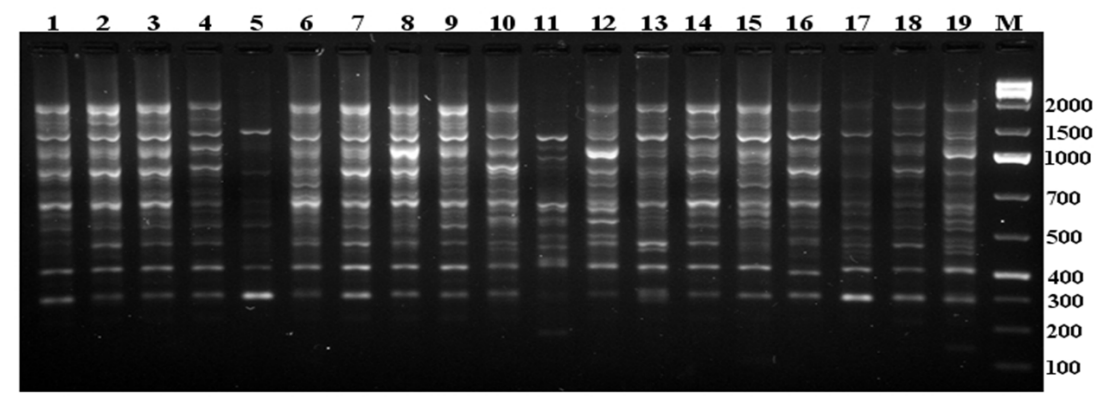

Fig. 2 The ISSR profiles obtained by primer UBC840, lanes 1 to 19: breeding lines $111,158,170,152,159,110,151,156,20,28,16,175,1661,114,2,5,122,1720$, 115, M: 1 kb DNA ladder (Fermentas, SM1303) 
Tab. 3. Total loci, polymorphic loci, PPL, He, I and Ne of ISSR primers in 101 bread wheat genotypes

\begin{tabular}{|c|c|c|c|c|c|c|c|}
\hline Primer name & Total loci & $\begin{array}{c}\text { Poly- } \\
\text { morphic loci }\end{array}$ & PPL* & $\mathrm{He}^{*}$ & $\mathrm{I}^{*}$ & $\mathrm{Ne}^{*}$ & Band size (bp) \\
\hline A13 & 10 & 9 & 90 & 0.31 & 0.48 & 1.50 & $200-1500$ \\
\hline UBC840 & 12 & 12 & 100 & 0.34 & 0.49 & 1.36 & $400-2000$ \\
\hline UBC 825 & 12 & 11 & 91 & 0.35 & 0.51 & 1.61 & $400-1500$ \\
\hline UBC848 & 11 & 6 & 54 & 0.34 & 0.50 & 1.60 & $200-1500$ \\
\hline $\mathrm{A} 15$ & 11 & 10 & 90 & 0.42 & 0.60 & 1.81 & $400-2000$ \\
\hline 441 & 13 & 10 & 76 & 0.48 & 0.67 & 1.92 & $300-2000$ \\
\hline UBC 818 & 10 & 9 & 90 & 0.41 & 0.58 & 1.75 & $75-700$ \\
\hline A14 & 11 & 10 & 90 & 0.26 & 0.37 & 1.48 & $300-2000$ \\
\hline UBC807 & 10 & 9 & 90 & 0.41 & 0.58 & 1.78 & $400-1500$ \\
\hline UBC857 & 10 & 6 & 60 & 0.27 & 0.42 & 1.42 & $500-2000$ \\
\hline UBC880 & 12 & 10 & 83 & 0.37 & 0.53 & 1.68 & $200-1500$ \\
\hline UBC864 & 14 & 12 & 85 & 0.39 & 0.55 & 1.73 & $200-1500$ \\
\hline UBC 855 & 13 & 11 & 84 & 0.41 & 0.58 & 1.80 & $300-1500$ \\
\hline UBC816 & 14 & 12 & 85 & 0.27 & 0.39 & 1.49 & $75-1000$ \\
\hline UBC827 & 11 & 7 & 63 & 0.26 & 0.38 & 1.46 & $200-1000$ \\
\hline UBC812 & 12 & 8 & 66 & 0.43 & 0.60 & 1.82 & $300-2000$ \\
\hline UBC811 & 10 & 9 & 90 & 0.31 & 0.44 & 1.58 & $300-1500$ \\
\hline UBC834 & 16 & 14 & 87 & 0.44 & 0.62 & 1.86 & $200-2000$ \\
\hline UBC 808 & 13 & 12 & 92 & 0.24 & 0.36 & 1.49 & $200-2000$ \\
\hline A12 & 10 & 10 & 100 & 0.48 & 0.67 & 1.91 & $300-2000$ \\
\hline UBC836 & 15 & 12 & 80 & 0.33 & 0.48 & 1.61 & $200-1500$ \\
\hline UBC844 & 7 & 5 & 71 & 0.30 & 0.43 & 1.55 & $400-1000$ \\
\hline UBC 820 & 10 & 10 & 100 & 0.41 & 0.60 & 1.74 & $200-1500$ \\
\hline Total & 267 & 224 & & & & & \\
\hline Mean & 11.6 & 9.7 & 83 & 0.36 & 0.51 & 1.65 & \\
\hline
\end{tabular}

*PPL: percentage of polymorphic loci, He: mean of expected heterozygocity, I: Shannon's information index, Ne: number of effective alleles

The Dice similarity coefficient values between 101 breeding lines were slightly higher than those for cultivars. cultivars and breeding lines ranged from 0.76 to 0.91 , av- The highest similarity value was obtained between breederaging $0.86,0.85$ and 0.85 for cultivars, breeding lines, ing lines 175 and 170 , while lines 121 and 151 were found and cultivars + breeding lines. The PPL, Ne, He and I for as genetically most dissimilar. Dice similarity coefficients

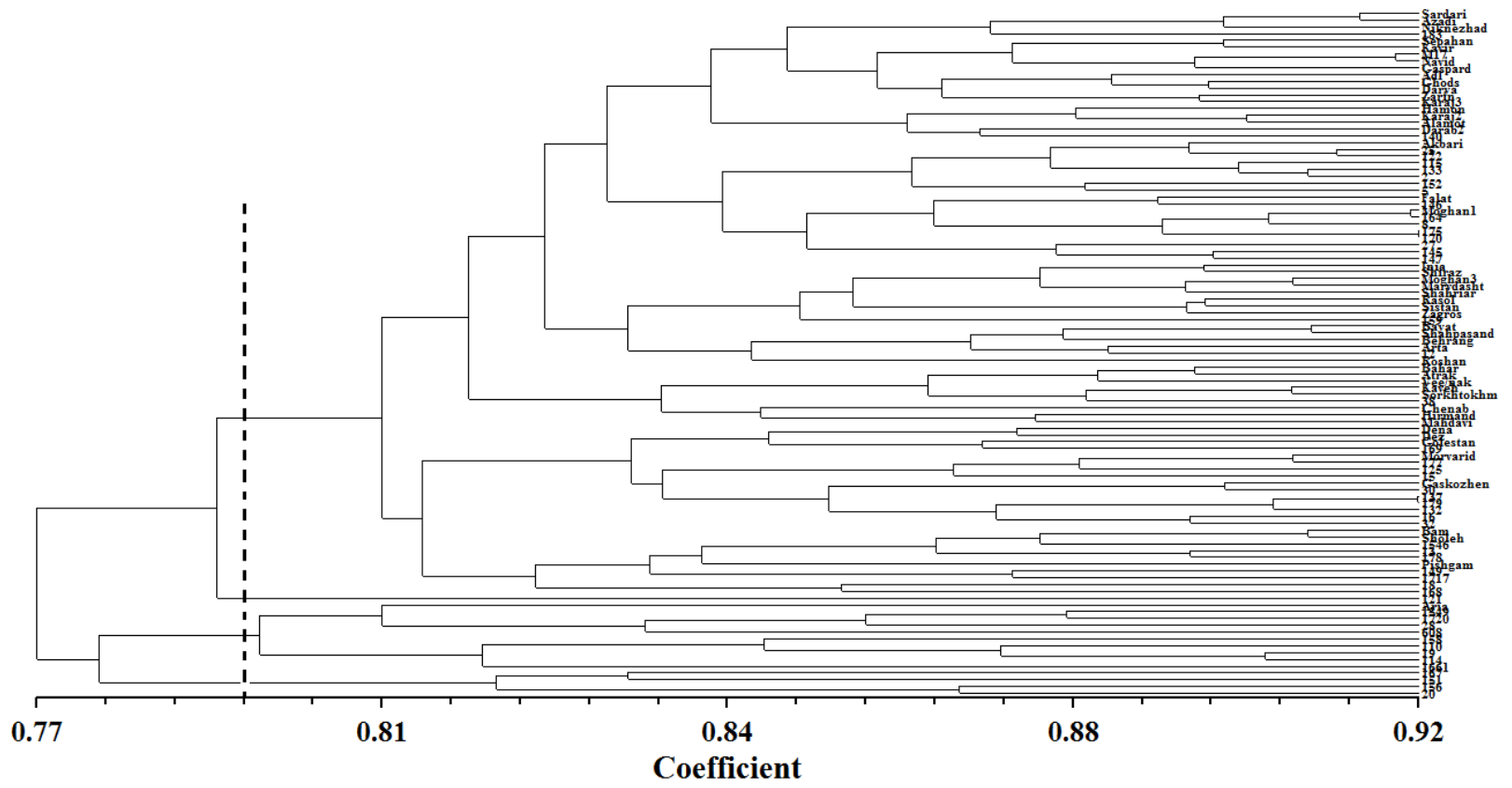

Fig. 3. Dendrogram of 101 bread wheat genotypes constructed with complete linkage method using Dice similarity coefficient based on 267 ISSR loci 
Tab. 4. Four clusters of 101 bread wheat cultivars and breeding lines identified by ISSR data

\begin{tabular}{|c|c|c|c|c|c|c|}
\hline \multicolumn{4}{|c|}{ Cluster I } & \multirow{2}{*}{$\begin{array}{c}\text { Cluster II } \\
121\end{array}$} & \multirow{2}{*}{$\frac{\text { Cluster III }}{\text { 'Aria' }}$} & \multirow{2}{*}{$\begin{array}{c}\text { Cluster IV } \\
167\end{array}$} \\
\hline 'Sardari' & 2 & 'Behrang' & 179 & & & \\
\hline 'Azadi' & 152 & 'Arta' & 132 & & 1549 & 151 \\
\hline 'Niknezhad' & 5 & 12 & 16 & & 1720 & 156 \\
\hline 183 & 'Falat' & 'Roshan' & 32 & & 28 & 20 \\
\hline 'Sepahan' & 146 & 'Bahar' & 'Bam’ & & 608 & \\
\hline 'Kavir' & 'Moghanl' & 'Atrak' & 'Sholeh' & & 158 & \\
\hline 'M17’ & 164 & 'Vee/nak' & 1546 & & 110 & \\
\hline 'Navid' & 8 & 'Kaveh' & 13 & & 19 & \\
\hline 'Gaspard' & 175 & 'Shorkhtokhm' & 178 & & 114 & \\
\hline 'Adl' & 170 & 38 & 'Pishgam' & & 1661 & \\
\hline 'Ghods' & 27 & ‘Chenab & 149 & & & \\
\hline 'Darya' & 145 & 'Hirmand' & 1717 & & & \\
\hline 'Zarin' & 147 & 'Mahdavi' & 18 & & & \\
\hline 'Karaj3' & 'Inia' & 'Dena' & 168 & & & \\
\hline 'Hamun' & 'Shiraz' & 'Dez' & & & & \\
\hline 'Karaj2' & 'Moghan3' & 'Golestan’' & & & & \\
\hline 'Alamut' & 'Marvdasht' & 169 & & & & \\
\hline 'Darab2' & 'Shahriar' & 'Morvarid' & & & & \\
\hline 140 & 'Rasul' & 177 & & & & \\
\hline 'Akbari' & 'Sistan' & 125 & & & & \\
\hline 25 & 'Zagros' & 15 & & & & \\
\hline 122 & 159 & 'Gaskozhen' & & & & \\
\hline 115 & 'Bayat' & 30 & & & & \\
\hline 133 & 'Shahpasand' & 137 & & & & \\
\hline
\end{tabular}

with complete linkage clustering algorithm grouped the 101 wheat genotypes into four clusters. Most of the cultivars and breeding lines located in cluster I. Cluster II consisted of one sample, line 121. All cultivars were in the vicinity of each other in cluster I except for cultivar Aria which is in cluster III (Fig 3 and Tab. 4). PCoA was performed to visualize the association among lines and cultivars. The first two components of PCoA explained 7.6\% of the total variation, probably suggesting the evenly dis- tribution of amplified loci in wheat genome and no considerable correlation between them (Fig. 4).

\section{Discussion}

In the current investigation, 50 agro-economically important Iranian bread wheat cultivars and 51 breeding lines were examined via ISSR markers at a molecular level. A high level of polymorphism (82.77\%) was revealed by 23 anchored dinuclotide ISSR primers, showing the high dis-

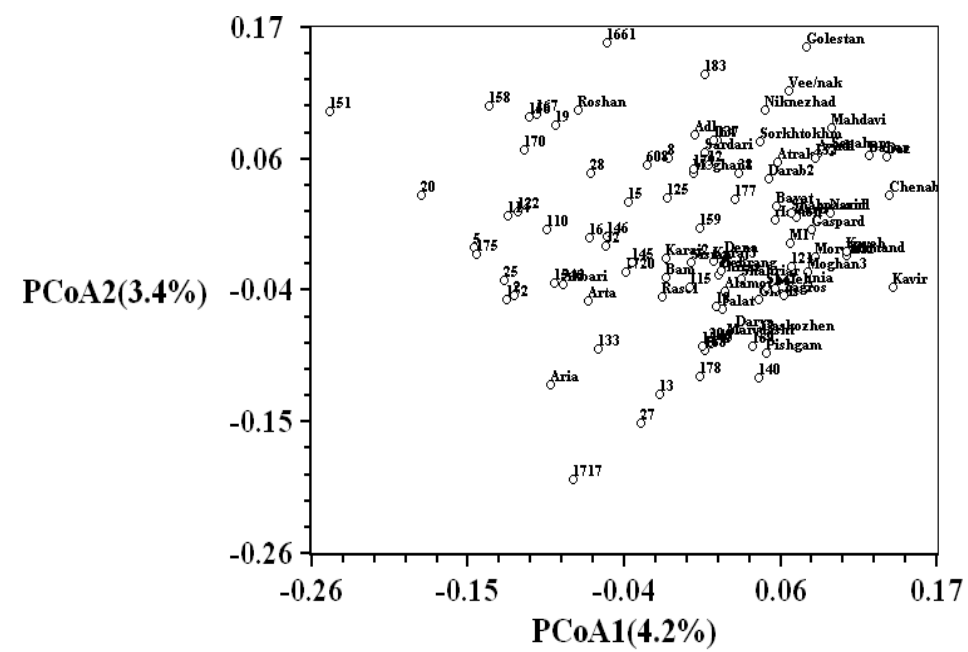

Fig. 4. Principle coordinate analysis plot of 101 bread wheat cultivars and breeding lines revealed by ISSR data 
criminative and resolving power of the used ISSRs in the studied germplasm of bread wheat. The high percentage of polymorphism detected by ISSR markers have been reported in Portuguese bread wheat cultivars (98.5\%) (Carvalho et al., 2010), in Chinese barley accessions (98.13\%) (Hou et al., 2005), and in Mediterranean faba bean cultivars (98.9\%) (Terzopoulos and Bebeli, 2008). Nagaoka and Ogihara (1997) stated that primers with dinucleotide motifs constituted more suitable primers for amplifying ISSRs in wheat, regardless of whether the genotype is diploid, tetraploid, or hexaploid. Blair et al. (1999) also considered dinucleotide motif primers to be more amenable to ISSR analysis in rice, but primers based on the more infrequent trinucleotide and tetranucleotide SSRs amplified few bands in rice (Blair et al., 1999). Carvalho et al. (2010) reported a high level of polymorphism by using the pentanucleotide primer UBC880 [(GGAGA $\left.)_{3}\right]$ in bread and durum wheat. In this study, a few tri- and teranucleotide ISSR primers amplified no clear and polymorphic banding patterns. A result similar to ours was reported by $\mathrm{Na}$ japhy et al. (2012). ISSR primers UBC820, UBC840, and A12 with the dinucleotide motifs GA and GT produced $100 \%$ polymorphism.

A narrow range of Dice genetic similarity ( 0.76 to 0.91 ) was found within the studied germplasm, indicating the limited amount of genetic diversity in Iranian bread wheat cultivars. This was confirmed by the low values of I and He obtained in our investigation. Mohammadi et al. (2009) reported the high values of SSR-based gene diversity and polymorphic information content (PIC) of 0.7 and 0.66 for 27 Iranian local commercial and adapted wheat cultivars. The differences between that investigation and our study may be derived from the different number of studied samples and used marker systems. Carvalho et al. (2010) detected considerable genetic diversity among the old Portuguese wheat cultivars using ISSR markers. Several authors reported a narrow genetic diversity in wheat when assessed with RAPD and DNA amplification fingerprinting (DAF) (Abdollahi Mandoulakani et al., 2010), AFLPs (Khalighi et al., 2008; Shoaib and Arabi, 2006), and selective amplified microsatellite polymorphic loci (SAMPL) (Altintas et al., 2008). Nevertheless, other researchers reported that ISSRs supplanted the polymorphism rates achieved by other markers in wheat and other plant species (Nagaoka and Ogihara, 1997). AMOVA was conducted to partition variance components among cultivars and breeding lines. Higher level of genetic variation detected within cultivars+breeding lines (97\%) compared to among cultivars and breeding lines, indicating that overall genetic differentiation among lines and cultivars was low ( $p=0.01$, PhiPT $=0.028$ ).

A cluster analysis using the Dice similarity coefficient and a complete linkage algorithm identified four clusters. The most of the cultivars and breeding lines were in the cluster I. No cultivars were located in cluster II, III, and IV except Aria in cluster III. The breeding lines were dis- persed in four clusters, although most of them were in cluster I. These results confirmed the limited and narrow genetic diversity found in Iranian cultivated bread wheat germplasm. Different wheat breeding programs in recent decades have reduced the genetic variability of Iranian commercial wheat cultivars. This can be evidenced by epidemic extension of wheat yellow rust and other biotic and abiotic stresses in most regions of Iran under cultivation of bread wheat in the recent years. A decrease in allelic diversity after the 1960's was demonstrated in a study of 559 French bread wheat accessions from year 1800 to 2000 using 42 SSRs (Roussel et al., 2004) and in 480 European wheat cultivars from 1840 to 2000 using 39 SSRs (Roussel et al., 2005). The genetically most dissimilar breeding lines were found as 121 and 151. Knowledge about the genetic relationships of genotypes provides useful and helpful information for germplasm management and for planning intraspecific crosses between highly diverse cultivars for wheat breeding programs. Hence, the breeding lines with sufficient genetic distance could be introduced as potentially appropriate parents in wheat breeding programs to explore heterosis as well as to produce mapping populations, provided that factors such as combining ability and other agronomically important traits are considered.

\section{Conclusions}

Knowledge of the level of genetic variation among accessions is a prerequisite for germplasm conservation and breeding programs. The current study demonstrated that the genetic basis of Iranian bread wheat germplasm has been narrowed and more new accessions and landraces should be introduced to this germplasm to extend its diversity for further use in wheat breeding programs. The ISSR technique is an efficient tool for classifying wheat cultivars but more primers and different molecular marker systems need to be combined for an accurate and comprehensive assessment of genetic diversity and to develop cultivar-specific markers in Iranian bread wheat germplasm. However, the resulting groups classified by ISSRs already can be used as sources of genotypes appropriate for breeding programs in wheat.

\section{Acknowledgements}

The authors are grateful for the financial support provided by Faculty of Agriculture and Institute of Biotechnology, Urmia University, Iran.

\section{References}

Abdollahi Mandoulakani B, Shahnejat-Bushehri AA, Sayed Tabatabaei BE, Torabi S, Mohammadi Hajiabad A (2010). Genetic diversity among wheat cultivars using molecular markers. J Crop Improv 24:299-309.

Altintas S, Toklu F, Kafkas S, Kilian B, Brandolini A, Ozkan $\mathrm{H}$ (2008). Estimating genetic diversity in durum and bread 
260

wheat cultivars from Turkey using AFLP and SAMPL markers. Plant Breed 127:9-14.

Archak S, Gaikwad AB, Gautam D, Rao EV, Swamy KR, Karihaloo JL (2003). Comparative assessment of DNA fingerprinting techniques (RAPD, ISSR and AFLP) for genetic analysis of cashew (Anacardium occidentale L.) accessions of India. Genome 3:362-369.

Blair MW, Panaud O, McCouch SR (1999). Inter-simple sequence repeat (ISSR) amplification for analysis of microsatellite motif frequency and fingerprinting in rice (Oryza sativa L.). Theor Appl Genet 98:780-792.

Bornet B, Branchard M (2001). Nonanchored inter simple sequence repeat (ISSR) markers: reproducible genome fingerprinting. Plant Mol Biol Rep 19:209-215.

Briggle LW, Curtis BC (1987). Wheat Worldwide. In "Wheat and Wheat Improvement", EG Heyne, ed Ed. 2nd. American Society of Agronomy Inc. Publishers, Madison, Wisconsin, $31 \mathrm{p}$.

Carvalho A, Guedes-Pinto H, Martin-Lopes, Lima-Brito P (2010). Genetic variability of old Portuguese bread wheat cultivar assayed by IRAP and REMAP markers. Ann Appl Biol 156:337-345.

Doyle JJ, Doyle JL (1990). Isolation of plant DNA from fresh tissue. Focus 12:13-15.

Dreisigacker S, Zhang P, Warburton ML, Skovmand D, Hoisington D, Melchinger AE (2005). Genetic diversity among and within CIMMYT wheat landrace accessions investigated with SSRs and implications for plant genetic resources management. Crop Sci 45:653-661.

Golkar P, Arzani A, Rezaei AM (2011). Genetic variation in safflower (Carthamus tinctorious L.) for seed quality-related traits and inter-simple sequence repeat (ISSR) markers. Int J Mol Sci 12:2664-2677.

Gupta PK, Balyan HS, Edwards KJ, Isaac P, Korzun V, Röder M, Gautier MF, Joudrier P, Schlatter AR, Dubcovsky J, De la Pena RC, Khairallah M, Penner G, Hayden MJ, Sharp P, Keller B, Wang RCC, Hardouin JP, Jack P (2002). Genetic mapping of 66 new microsatellite (SSR) loci in bread wheat. Theor Appl Genet 105:413-422.

Hou YC, Yan ZH,Wei YM, Zheng YL (2005). Genetic diversity in barley from west China based on RAPD and ISSR analysis. Barley Gen Newsletter 35:9-22.

Khalighi M, Arzani A, Poursiahbidi MM (2008). Assessment of genetic diversity in Triticum spp. and Aegilops spp. using AFLP markers. Afr J Biotech 7:546-552.

Lynch M, Milligan BG (1994). Analysis of population genetic structure with RAPD markers. Mol Ecol 3:91-99.

Mohammadi SA, Khodarahmi M, Jamalirad S, Jalal Kamali MR (2009). Genetic diversity in a collection of old and new bread wheat cultivars from Iran as revealed by simple sequence repeat-based analysis. Ann Appl Biol 154:67-76.
Myśków B, Milczarski P, Masojé P (2011). Comparison of RAPD, ISSR and SSR markers in assessing genetic diversity among rye (Secale cereale L.) inbred lines. Plant Breed Seed Sci 62:107-115.

Nagaoka T, Ogihara Y (1997). Applicability of inter-simple sequence repeat markers in wheat for use as DNA markers in comparison to RFLP and RAPD markers. Theor Appl Genet 94:597-602.

Najaphy A, Ashrafi Parchin R, Farshadfar E (2012). Comparison of phenotypic and molecular characterizations of some important wheat cultivars and advanced breeding lines. Aust J Crop Sci 2:326-332.

Peakall R, Smouse PE (2006). GenAlEx 6: Genetic analysis in excel. Population genetic software for teaching and research. Mol Ecol Notes 6:288-295.

Pradeep Reddy M, Sarla N, Siddiq EA (2002). Inter simple sequence repeat (ISSR) polymorphism and its application in plant breeding. Euphytica 128:9-17.

Rohlf FJ (2000). NTSYS-pc: numerical taxonomy and multivariate analysis system, version 2.1. Exeter Software, New York.

Roussel V, Koenig J, Beckert M, Balfourier F (2004). Molecular diversity in French bread wheat accessions related to temporal trends and breeding programs. Theor Appl Genet 108:920-930.

Roussel V, Leisova L, Exbrayat F, Stehno Z, Balfourier F (2005). SSR allelic diversity changes in 480 European bread wheat varieties released from 1840 to 2000. Theor Appl Genet 111:162-170.

Shoaib A, Arabi MIE (2006). Genetic diversity among Syrian cultivated and landraces wheat revealed by AFLP markers. Genet Resour Crop Evol 53:901-906.

Smolik M, Ochmian I, Smolik B (2011). RAPD and ISSR Methods Used for Fingerprinting Selected, Closely Related Cultivars of Aronia melanocarpa. Not Bot Horti Agrobo 39(2):276-284.

Sofalian O, Chaparzadeh N, Dolati M (2009). Genetic diversity in spring wheat landraces from Northwest of Iran assessed by ISSR markers. Not Bot Horti Agrobo 37(2):252-256.

Talbert LE, Blake NK, Chee PW, Blake TK, Magyar GM (1994). Evaluation of sequence-tagged-site-facilitated PCR products as molecular markers in wheat. Theor Appl Genet 87:789-794.

Terzopoulos PJ, Bebeli PJ (2008). Genetic diversity analysis of Mediterranean faba bean (Vicia faba L.) with ISSR markers. Field Crops Res 108:39-44.

Zietkiewicz E, Rajalski A, Labuda D (1994). Genome fingerprinting by simple sequence repeat (SSR) anchored polymerase chain reaction amplification. Genomics 20:176183. 